\title{
Analysis on the Performance of Steam Absorption Chiller at Various Operating Conditions
}

\author{
Rosnadiah Bahsan, Khairul Aizat Mohd Sarudin, Nor Merlisa Ali, Syamsul Nor Azlan Mohamad
}

\begin{abstract}
Steam Absorption Chiller (SAC) is the main component of Cogeneration Plant which provides chilled water by utilizing the steam as system input for the cooling purpose. In this paper, the performance of a double effect lithium bromide-water steam absorption chiller was analyzed by conducting the energy and exergy analysis. An excel spreadsheet program was developed to calculate the exergy destructions within the systems and total exergy loss of the system in guiding future improvement of the plant. Various operating conditions like steam inlet temperature, chilled water inlet temperature and load factor were analyzed in detail. The result showed that the highest exergy destruction occurred at the high temperature generator followed by the absorber. Increasing the load factor, steam and chilled water inlet temperature will increase the system performance.
\end{abstract}

Keywords: Cogeneration, COP, Energy Analysis, Exergy Analysis, Steam Absorption Chiller.

\section{INTRODUCTION}

District cooling system in Malaysia involves an environmental friendly technology that re-uses the waste heat from the electricity generation to lower the plant and system operating cost. This technology is known as cogeneration in which the waste heat encounters several processes that produce steam and this has been used in chilled water production with the help of an absorption chiller [1]. Cogeneration is also called as a combination of heat and power (CHP) system that is planned to produce both heat and power and will reduce more than $35 \%$ electricity cost as well as plenty of free cooling and, or heating for the industry [2].

The standard components for the absorption system are evaporator, absorber, condenser and generator. Vapor absorption system using water as the refrigerant and lithium bromide as the absorbent due to the negative effect of ammonia that contributes to greenhouse effect and ozone layer depletion [3]. The simplest and common type of vapor

Revised Manuscript Received on October 30, 2019.

Rosnadiah Bahsan, Faculty of Mechanical Engineering, Universiti Teknologi MARA, Selangor, Malaysia. Email: rosnadiah@uitm.edu.my

Khairul Aizat Mohd Sarudin, Operation Executive, Suria KLCC Sdn. Bhd., Kuala Lumpur, Malaysia.

Nor Merlisa Ali, Faculty of Mechanical Engineering, Universiti Teknologi MARA (UiTM), Selangor, Malaysia. Email: merlisa@uitm.edu.my.

Syamsul Nor Azlan Mohamad, Faculty of Education, Universiti Teknologi MARA (UiTM), Selangor, Malaysia. Email: syams9211@uitm.edu.my. absorption system is the single effect absorption system that uses low temperature of steam as the heat source [4].

The performance and operation of steam absorption chiller for gas district cooling plant at various operating conditions were studied. Kaushik et al. analyzed lithium bromide-water solution for single and double effect series flow vapor absorption system by energy analysis. The result shows that the COP double effect series flow lies between 1.0 and 1.28 while the single effect lies between 0.6 and 0.75 [5]. Lamine and Said performed the energy analysis of single effect absorption chiller and found that increasing the generator and evaporator temperature will increase the COP up to 0.8 [6]. Hongxi et al. studied an experiment model for a micro-scale double-effect absorption chiller and found that the increasing of actual cooling load from 4 to $17 \mathrm{~kW}$ will increase the performance up to 1.10 [7].

The entropy generation of each component and the total entropy generation of the entire system component were obtained [8]. A number of researchers performed an exergy analysis for a single and double effect water-lithium bromide absorption system and found that the largest exergy destruction has been recorded at the absorber and generator [9] - [11]. Mohtaram et al. analyzed the exergy analysis for an absorption refrigeration cycle with the working fluid of water lithium bromide by simulation. The result showed that the absorber is the highest contribution to exergy destruction [12]. Mehyo et al. determined the destruction and losses of exergy in system components under operating conditions by MATLAB ${ }^{\circledR}$ computer program and found that the efficiencies for cooling and heating applications have reached up to $0.295,1.295$ respectively [13]. Lake et al. also proved that the absorber, generator and condenser are the largest contribution to exergy destruction using engineering equation solver [14].

The study of SAC performance at PJ1 plant is important as the plant operates 24 hours a day and the chilled water supply depends on the SAC. Therefore, the current performance of the SAC needs to be evaluated continuously to make sure that it gives the decent performance throughout the day. This study is to analyze the energy and exergy efficiency at $\mathrm{PJ} 1$ plant based on 1st and 2nd law of thermodynamics and also to identify the effect of different operating conditions on the performance of SAC system. 


\section{Analysis on the Performance of Steam Absorption Chiller at Various Operating Conditions}

\section{SYSTEM DESCRIPTION}

The SAC system used in PJ1 Cogeneration plant is the double effect lithium-bromide/water type as presented in Fig. 1. The steam boiler and heat recovery steam generator will supply saturated steam to the SAC at the pressure of 8 bar and temperature of $178^{\circ} \mathrm{C}$ that are used for heat driving sources for the chilled water production. The capacity for this SAC system is $19000 \mathrm{RT}$ and it supplies the chilled water with the temperature range of $6^{\circ} \mathrm{C}-14^{\circ} \mathrm{C}$. Heat recovery steam generator receives condensate water from the SAC that flows through the hot water tank and generates saturated steam from that water source. Heat from the SAC is extracted with the help of water that comes from the cooling tower with $28^{\circ} \mathrm{C}$ enter temperature and $32^{\circ} \mathrm{C}$ temperature that returns back to the cooling tower.

The double-effect lithium bromide-water steam absorption chiller mainly consists of a high and low temperature generator, condenser, evaporator, absorber, high and low temperature heat exchanger, solution pump, expansion valve and refrigerant pump. The working principle starts with the weak lithium bromide solution at state 4 which is pumped to the high temperature generator at state 9 through high and low temperature heat exchanger. Saturated steam at state 25 will boil the weak solution and vaporize the refrigerant into primary refrigerant vapor and the weak solution is transformed into medium solution. Primary refrigerant vapor at state 10 is used as the heating source at low temperature generator to transform medium solution at state 14-15 into strong solution at state 17-18. The secondary refrigerant vapor at state 13 is introduced.

Primary refrigerant vapor flows into the expansion valve to reduce its temperature and pressure and it transforms into state 12 . Refrigerant vapor from state 12 and 13 condenses in the condenser by using the cooling water from state 19 and it transforms into water at state 1 before flows into the expansion valve and transforms into state 2. In the evaporator, water from state 2 absorbs heat from the chilled water that comes from state 21 and causes it to evaporate. The evaporate water at state 3 flows into the absorber and the strong solution from state 18 absorbs the water while the weak solution at state 3 is pumped back to state 9 and the cycle starts over again.

\section{A. Theoretical Consideration:}

The following assumptions have been made for the analysis of the system:

- The cycle in steady state conditions;

- The heat losses and pressure drop in all cycle lines and system components are negligible.

- The processes at all expansion valves are assumed to be adiabatic, resulting in constant enthalpy processes.

- Heat transfer from surroundings to the system or vice versa is negligible.

- Steam inlet to be saturated vapor and steam outlet to be saturated liquid.

- The refrigerant states leaving the condenser is saturated liquid and refrigerant states leaving the evaporator is saturated vapor.

- The atmospheric surrounding temperature and pressure is assumed at $25^{\circ} \mathrm{C}$ and $1 \mathrm{~atm}$ to simplify the analysis.

- The concentration of lithium bromide can be calculated. Thermodynamic properties of lithium bromide-water solution are referred to Ahmadul Ameen [15].

- This analysis is applied on a steam absorption chiller in PJ1 Plant which is SAC-0130-E.

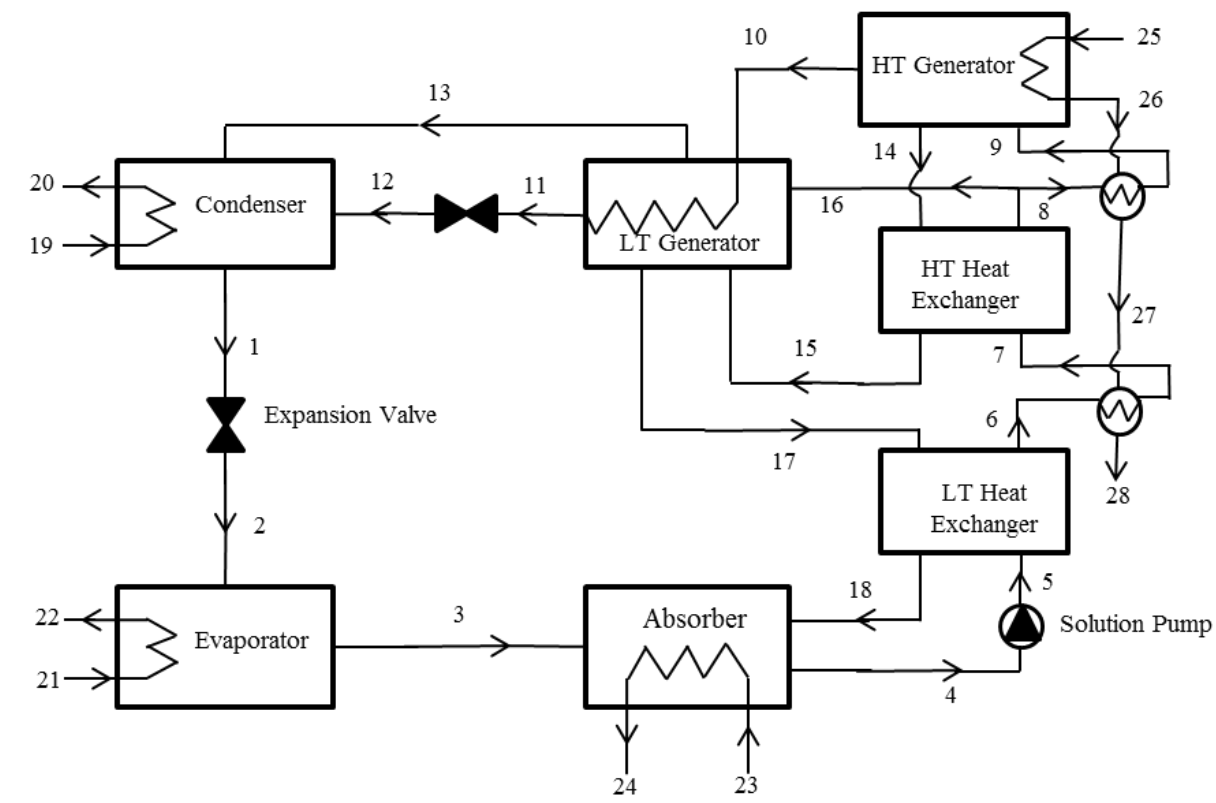

Fig. 1. Schematic diagram of the double effect steam absorption chiller 


\section{THERMODYNAMIC ANALYSIS}

The first and second principles of thermodynamics are applied to analyze the SAC systems which involve the application of conservation of mass, conservation of concentration, energy and exergy equations. The equations of these principles are stated below [5], [9] and [11]:

\section{A. Conservation of mass:}

Conservation of mass law for each component in the system can be expressed as:

$\Sigma \dot{m}_{i}=\Sigma \dot{m}_{o}$

The principle for each component of the cycle is written as:

$$
\begin{aligned}
& \dot{m}_{1}=\dot{m}_{2}=\dot{m}_{3} \\
& \dot{m}_{3}+\dot{m}_{18}=\dot{m}_{4} \\
& \dot{m}_{4}=\dot{m}_{5}=\dot{m}_{6}=\dot{m}_{7}=\dot{m}_{8} \\
& \dot{m}_{8}=\dot{m}_{9}+\dot{m}_{16} \\
& \dot{m}_{9}=0.7 \dot{m}_{8} \\
& \dot{m}_{16}=0.3 \dot{m}_{8} \\
& \dot{m}_{9}=\dot{m}_{14}+\dot{m}_{10} \\
& \dot{m}_{14}=\dot{m}_{15} \\
& \dot{m}_{17}=\dot{m}_{18} \\
& \dot{m}_{16}+\dot{m}_{15}=\dot{m}_{13}+\dot{m}_{17} \\
& \dot{m}_{10}=\dot{m}_{11}=\dot{m}_{12} \\
& \dot{m}_{19}=\dot{m}_{20}=\dot{m}_{23}=\dot{m}_{24} \\
& \dot{m}_{21}=\dot{m}_{22} \\
& \dot{m}_{25}=\dot{m}_{26}=\dot{m}_{27}=\dot{m}_{28}
\end{aligned}
$$

\section{B. Conservation of concentration}

The principle of concentration conservation for each component is written as:

$\Sigma \dot{m}_{i} X_{i}=\Sigma \dot{m}_{o} X_{o}$

The principle for each component of the cycle is written as :

$\dot{m}_{18} X_{18}=\dot{m}_{4} X_{4}$

$\dot{m}_{9} X_{9}=\dot{m}_{14} X_{14}$

$X_{4}=X_{5}=X_{6}=X_{7}=X_{8}=X_{9}=X_{16}$

$X_{14}=X_{15}$

$X_{17}=X_{18}$

\section{Energy analysis}

The first law of thermodynamics for the system is written as:

$Q_{\text {net }}-W_{\text {net }}=\Sigma_{\text {out }} \dot{m}_{\text {out }}\left(h_{\text {out }}+K E_{\text {out }}+P E_{\text {out }}\right)-\sum_{\text {in }} \dot{m}_{\text {in }}\left(h_{\text {in }}+\right.$ $\left.K E_{\text {in }}+P e_{\text {in }}\right)$

The changes of kinetic and potential energy in the system are neglected and assuming that the systems are in steady state conditions, the first law of thermodynamics per unit mass is written as: $q+h_{i}=h_{o}+w$

The first law for different components is written as:

$h_{1} \approx h_{2}$

$h_{11} \approx h_{12}$

$Q_{C}=\dot{m}_{20}\left(h_{20}-h_{19}\right)$

$Q_{L}=\dot{m}_{21}\left(h_{21}-h_{22}\right)$

$Q_{A}=\dot{m}_{24}\left(h_{24}-h_{23}\right)$

$Q_{H T G}=\dot{m}_{25}\left(h_{25}-h_{26}\right)$

$C O P=\frac{Q E}{Q H T G}$

The circulation ratio is written as:

$C R=\frac{\dot{m} 5}{\dot{m} 1}$

The load factor is written as:

$\mathrm{LF}=\frac{Q L x Q .284}{R T}$

\section{Exergy analysis}

The analysis of the system exergy is written as follow:

$\Sigma \dot{m}_{i} e_{i}-\Sigma \dot{m}_{o} e_{o}+\dot{Q}\left(1-\frac{T o}{T i}\right)-\dot{W}-\dot{E}_{D}=0$

The third term is the heat exergy, where it is positive when the heat is transferred to the system. $W$ is the mechanical work transferred from or to the system. $\dot{E}_{\mathrm{D}}$ is the exergy destroyed due to the inside irreversibility. The kinetic and potential energies are neglected and noting that the chemical exergy is zero, the specified exergy is written as [18]:

$e x=\left(h-h_{o}\right)-T_{o}\left(s-s_{o}\right)$

The exergy losses for each system component are written as:

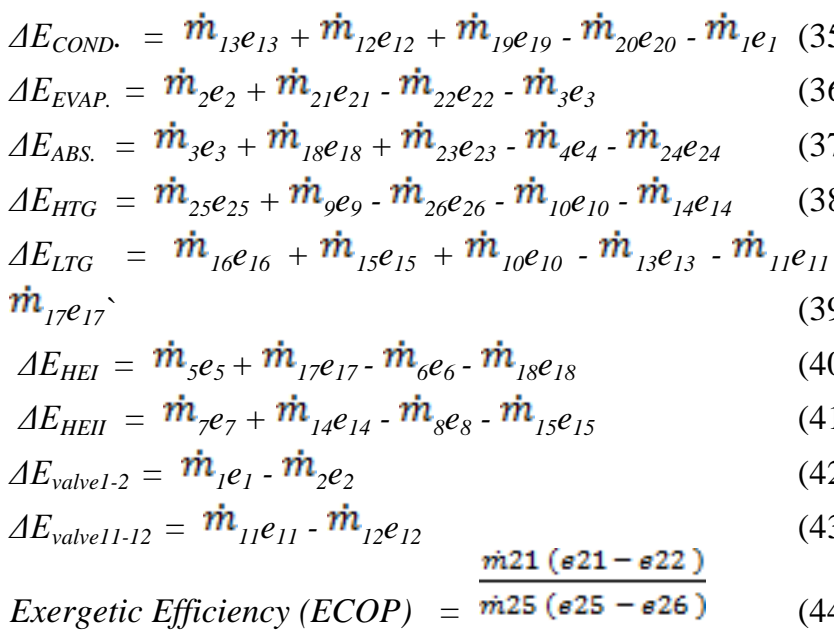




\section{Analysis on the Performance of Steam Absorption Chiller at Various Operating Conditions}

The performance analysis was carried out using an excel spreadsheet program. The initial condition read into the program includes the ambient conditions, all state temperatures and mass flow rate. The spreadsheet program determines all the points of the cycle inclusive of enthalpy, entropy, coefficient of performance and exergetic efficiency. The results are presented in Table I, Table II and Table III. The work input to the solution pump and the frictional losses are negligible to simplify the analysis.

Table- I: The thermodynamic properties for different states of the system

\begin{tabular}{|c|c|c|c|c|c|c|}
\hline Point & T & h & m & X & S & ex \\
\cline { 2 - 7 } & ${ }^{\circ}$ C & kJ/kg & $\mathrm{kg} / \mathbf{s}$ & $\%$ & $\mathrm{~kJ} / \mathrm{kg} . \mathrm{K}$ & $\mathrm{kJ} . \mathrm{kg}$ \\
\hline $\mathbf{l}$ & 37.5 & 157.09 & 3.22 & 0 & 0.539 & 1.06 \\
\hline $\mathbf{2}$ & 5.94 & 157.09 & 3.22 & 0 & 0.563 & -6.14 \\
\hline $\mathbf{3}$ & 5.94 & 2511.81 & 3.22 & 0 & 9.002 & -167.34 \\
\hline $\mathbf{4}$ & 39.5 & 91 & 49.14 & 57 & 0.230 & 22.49 \\
\hline $\mathbf{5}$ & 39.5 & 91 & 49.14 & 57 & 0.230 & 22.49 \\
\hline $\mathbf{6}$ & 54.7 & 123 & 49.14 & 57 & 0.385 & 8.30 \\
\hline $\mathbf{7}$ & 61.4 & 145 & 49.14 & 57 & 0.351 & 40.43 \\
\hline $\mathbf{8}$ & 117.8 & 256 & 49.14 & 57 & 0.670 & 56.37 \\
\hline $\mathbf{9}$ & 124.9 & 264 & 34.40 & 57 & 0.688 & 59.01 \\
\hline $\mathbf{1 0}$ & 140.5 & 2734.13 & 0.59 & 0 & 6.925 & 673.93 \\
\hline $\mathbf{1 1}$ & 140.5 & 591.35 & 0.59 & 0 & 1.744 & 76.23 \\
\hline $\mathbf{1 2}$ & 37.5 & 591.35 & 0.59 & 0 & 1.905 & 28.33 \\
\hline $\mathbf{1 3}$ & 72.3 & 2630.01 & 2.63 & 0 & 7.720 & 332.90 \\
\hline $\mathbf{1 4}$ & 140.5 & 301 & 33.81 & 58 & 0.749 & 76.89 \\
\hline $\mathbf{1 5}$ & 76.3 & 180 & 33.81 & 58 & 0.423 & 54.04 \\
\hline $\mathbf{1 6}$ & 117.8 & 256 & 14.74 & 57 & 0.670 & 56.37 \\
\hline $\mathbf{1 7}$ & 72.3 & 172 & 45.92 & 61 & 0.430 & 43.92 \\
\hline $\mathbf{1 8}$ & 43.2 & 112 & 45.92 & 61 & 0.180 & 58.42 \\
\hline $\mathbf{1 9}$ & 30 & 125.74 & 486.11 & - & 0.437 & 0.11 \\
\hline $\mathbf{2 0}$ & 38 & 159.17 & 486.11 & - & 0.546 & 1.06 \\
\hline $\mathbf{2 1}$ & 12 & 50.41 & 300.28 & - & 0.181 & 1.07 \\
\hline $\mathbf{2 2}$ & 5.98 & 25.14 & 300.28 & - & 0.091 & 2.62 \\
\hline $\mathbf{2 3}$ & 30 & 125.74 & 486.11 & - & 0.437 & 0.11 \\
\hline $\mathbf{2 4}$ & 36.9 & 154.58 & 486.11 & - & 0.531 & 0.94 \\
\hline $\mathbf{2 5}$ & 170 & 2767.9 & 3.11 & - & 6.665 & 785.18 \\
\hline $\mathbf{2 6}$ & 170 & 719.08 & 3.11 & - & 2.042 & 115.09 \\
\hline $\mathbf{2 7}$ & - & - & - & - & - & - \\
\hline $\mathbf{2 8}$ & 70 & 293.07 & - & - & 0.955 & 13.01 \\
\hline & & & & & & \\
\hline
\end{tabular}

Table- II: Energy flows for various components of SAC

\begin{tabular}{|l|l|}
\hline \multicolumn{1}{|c|}{ Component } & Energy flow, kW \\
\hline Evaporator, $\mathrm{Q}_{\mathrm{L}}$ & 7588.08 \\
\hline Absorber, $\mathrm{Q}_{\mathrm{A}}$ & 14019.41 \\
\hline Condenser, $\mathrm{Q}_{\mathrm{C}}$ Temperature & 6371.83 \\
\hline $\begin{array}{l}\text { High } \\
\text { Generator, } \mathrm{Q}_{\mathrm{HTG}}\end{array}$ \\
\hline COP & 1.19 \\
\hline
\end{tabular}

Table- III: Exergy flows at various components of SAC

\begin{tabular}{|l|c|c|}
\hline \multicolumn{1}{|c|}{ Component } & $\begin{array}{c}\text { Exergy } \\
\text { losses, } \mathbf{k W}\end{array}$ & $\begin{array}{c}\text { Exergy } \\
\text { losses } \mathbf{( \% )}\end{array}$ \\
\hline Evaporator, $\Delta \mathrm{E}_{\mathrm{L}}$ & 54.04 & 2.23 \\
\hline Absorber, $\Delta \mathrm{E}_{\mathrm{A}}$ & 635.79 & 26.22 \\
\hline Condenser, $\Delta \mathrm{E}_{\mathrm{C}}$ & 427.86 & 17.64 \\
\hline $\begin{array}{l}\text { High Temperature } \\
\text { Generator, } \Delta \mathrm{E}_{\mathrm{HTG}}\end{array}$ & 1080.71 & 44.57 \\
\hline $\begin{array}{l}\text { Low Temperature } \\
\text { Generator, } \Delta \mathrm{E}_{\mathrm{LTG}}\end{array}$ & 120.32 & 4.96 \\
\hline Heat Exchanger I, $\Delta \mathrm{E}_{\mathrm{HEI}}$ & 31.49 & 1.29 \\
\hline Heat Exchanger II, $\Delta \mathrm{E}_{\mathrm{HEII}}$ & 23.12 & 0.95 \\
\hline Valve 1-2, $\Delta \mathrm{E}_{\mathrm{VALVE1-2}}$ & 23.21 & 0.96 \\
\hline Valve $11-12, \Delta \mathrm{E}_{\mathrm{VALVE} 11-12}$ & 28.41 & 1.17 \\
\hline Total exergy losses & 2424.95 & - \\
\hline ECOP & \multicolumn{2}{|c|}{} \\
\hline
\end{tabular}

\section{RESULTS AND DISCUSSION}

The study on the performance of SAC system was conducted based on the energy and exergy analysis, and different operating conditions such as steam inlet temperature, chilled water inlet temperature and load factor. The result obtained is shown in Fig. 2 until Fig. 10.

Fig. 2 shows the exergy loss of SAC components in the system. The HP generator contributed to the highest exergy losses followed by the absorber and condenser. The HP generator contributed about $44.60 \%$ of the total exergy losses followed by the absorber with $26.22 \%$ and condenser with $17.64 \%$. The highest losses in the HP generator is caused by the separation losses in which a great amount of heat is needed to separate the refrigerant from the lithium bromide solution and to evaporate the refrigerant into the refrigerant vapor state. Another reason related to the losses is the high temperature difference between the working fluid and the input heat. The exergy loss in the absorber is caused by the heat of mixing to evaporate the refrigerant vapor with the strong lithium bromide solution. The extra cooling requirement to condense the refrigerant vapor from the generator is the reason for the exergy loss in the condenser. The HP generator contributed to the highest exergy losses followed by the absorber [10] and [16] which well matched to the results of this study. 


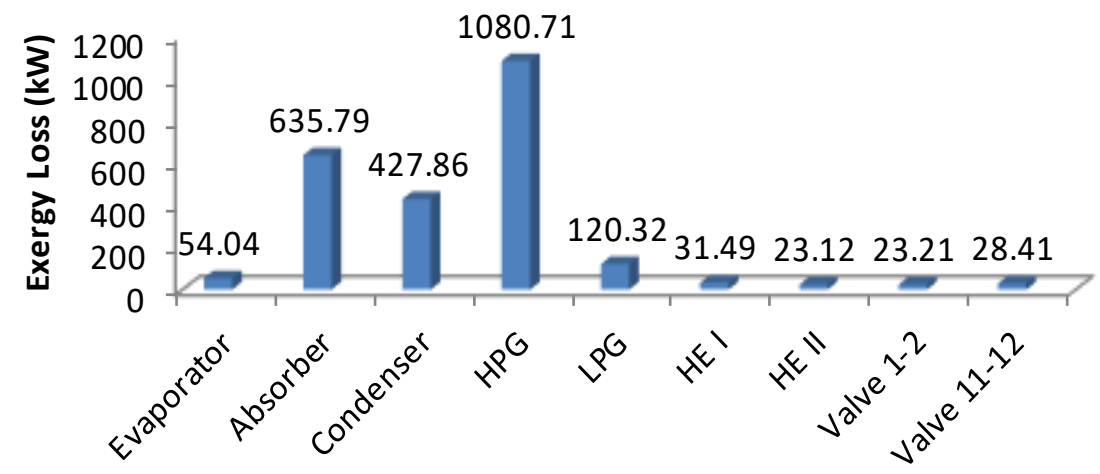

Component

Fig. 2. The exergy losses of the SAC components.

\section{A. Coefficient of performance (COP) and Exergetic Efficiency (ECOP) of the SAC system}

Fig. 3 shows the different value of COP and ECOP for a week period starting from day 1 until day 7 . The COP of the system fluctuated with the highest value for the COP was recorded on day 6 and the lowest value for the COP was recorded on day 1 which was 1.69 and 1.24 respectively. Day 6 recorded the highest COP due to the fact that Monday is the first working day that needs a higher cooling capacity; thus this increases the system performance while day 1 and day 2 are public holidays that require less cooling capacity compared to the working day. The ECOP for the system shows the same behavior like the COP. The highest ECOP was reported on day 4 and day 6 and the lowest ECOP was reported on day 1 and day 2 which were 0.27 and 0.23 respectively. This can be explained by the fact that the exegetic efficiency can perform well with the lower operating temperature and higher cooling capacity on the absorber.

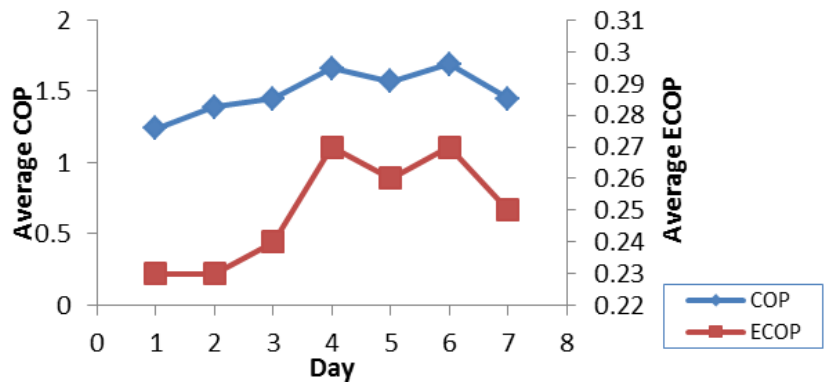

Fig. 3. Average COP and ECOP for a week period

\section{B. Average Load Factor (LF) of SAC system}

Fig. 4 shows the different value of Load Factor (LF) for a week period. The average LF for the system fluctuated with the highest LF recorded on day 6 which was 1.136 and the lowest was recorded on day 1 which was 0.879 . The decent value for the load factor is strongly influenced by the daily production capacity of chilled water for a week period. There are several factors that influence the production capacity of chilled water which are water quality, pipe condition, pump capacity and system performance. The good water quality with no debris will ensure the smooth and steady flow of the chilled water. The good pipe condition with no leaking part will ensure the smooth production of the chilled water and also the suitable pump capacity will pump the water steadily throughout the system. Moreover, the good system performance can be related with the system components that are in good working condition and well function. The lowest possible temperature of chilled water can be produced when the important factors are well managed.

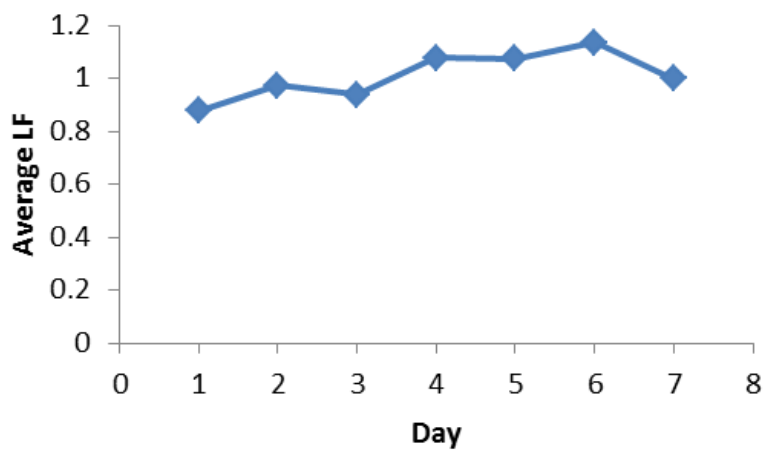

Fig. 4. Average LF for a week period

\section{Variable Operating Conditions}

- Steam Inlet Temperature: Fig. 5 shows the different value of COP and ECOP with the variation of steam inlet temperature. Increasing steam inlet temperature from $170^{\circ} \mathrm{C}$ to $200^{\circ} \mathrm{C}$ will slightly increase COP system from 1.34 to 1.41 . The increasing value for the COP of the system is strongly influenced by the operating temperature within the system. The increase of steam inlet temperature slightly reduces the amount of energy flow in the High Pressure Generator (HPG), thus increases the system performance. The COP is expected to increase more with the increasing of steam inlet temperature. On the other hand, the system ECOP slightly decreases from 0.269 to 0.252 with the increase of steam inlet temperature. The different behavior shown by the ECOP is caused by the fact that more exergy losses occur in the generator during the heat transfer process when more input exergy is supplied to the system. The COP and ECOP against steam inlet temperature show a positive understanding with the study conducted by others [5], [17] - [19]. 


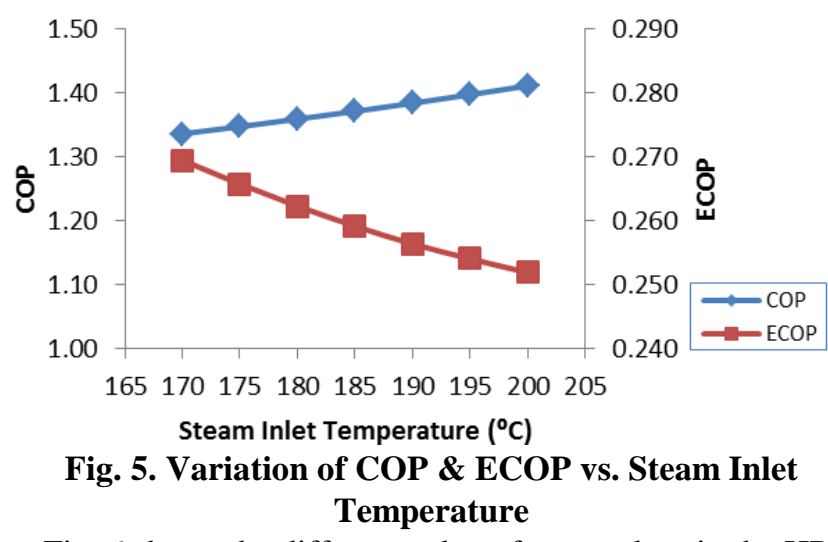

Fig. 6 shows the different value of exergy loss in the HPG with the variation of steam inlet temperature from $170^{\circ} \mathrm{C}$ to $200^{\circ} \mathrm{C}$. The exergy losses moderately increase from 778.43 $\mathrm{kW}$ to $908.46 \mathrm{~kW}$ with the increase of steam inlet temperature. The exergy losses at the other system component remain stable due to the theoretical assumption that there is no change on other temperature component of the system. The increasing value of exergy losses in HPG is strongly influenced by the temperature difference between the working fluid and the input steam. The exergy loss at other component is expected to increase with the increasing of other component temperature especially the temperature of primary refrigerant vapor and medium lithium bromide solution that flows out from the HPG. In addition, Gebrelassie et al. performed the exergy analysis on absorption system and found that the total exergy losses increase with the increasing of steam inlet temperature [10].

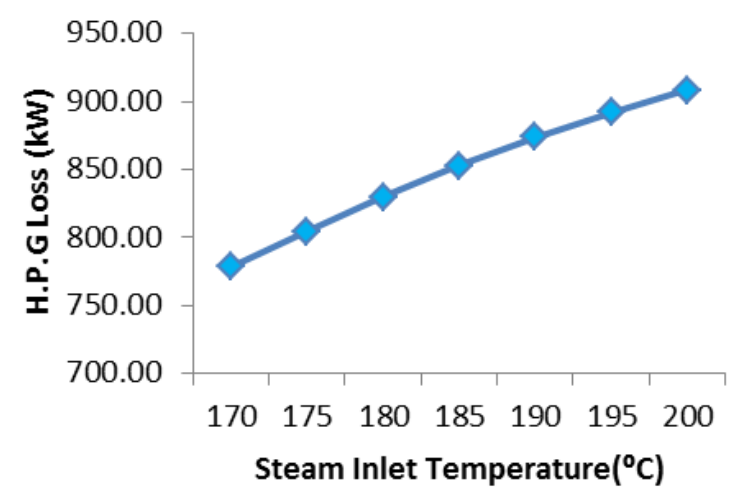

Fig. 6. HPG loss vs. Steam Inlet Temperature

- Chilled Water Inlet Temperature: Fig. 7 shows the different value of COP and ECOP with the difference of chilled water inlet temperature. The system COP rapidly increases from 1.12 to 1.56 with the gain of chilled water inlet temperature from $11^{\circ} \mathrm{C}$ to $13^{\circ} \mathrm{C}$. The increasing value for the COP of the system is influenced by the cooling capacity produced by the evaporator. More cooling capacity can be produced with the increasing chilled water inlet temperature. The COP is expected to increase more with the increasing of chilled water inlet temperature. The system ECOP slightly decreasing from 0.225 to 0.219 by increasing the chilled water inlet temperature. The different behavior shown by the ECOP is caused by the fact the absorption cooling system has higher ECOP at lower operating temperature in which low temperature has high potential to create the cooling effect at the same mass flow rate. The COP and ECOP against chilled water inlet temperature show a good result with the study conducted by others [5] and [18].

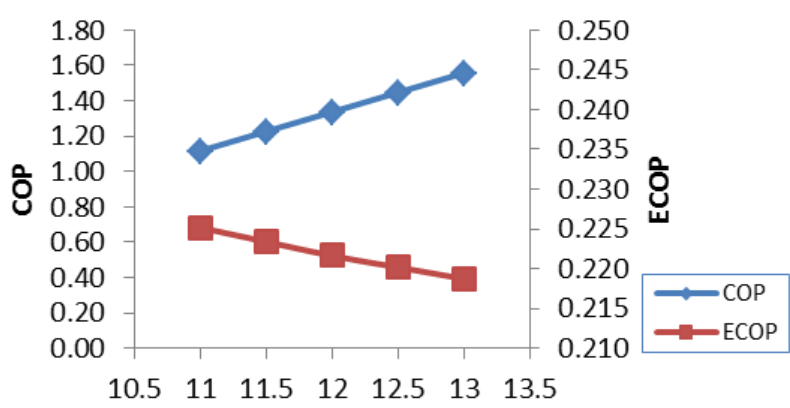

Chilled Water Inlet Temperature $\left({ }^{\circ} \mathrm{C}\right)$

\section{Fig. 7. COP \& ECOP vs. chilled water inlet} temperature

Fig. 8 shows the different value of exergy loss at different system component with the increasing of chilled water temperature. The increment of exergy loss at the system component especially at the absorber and condenser is strongly influenced by the mass flow rate of the system. The increment of chilled water inlet temperature by $0.50^{\circ} \mathrm{C}$ will increase the system mass flow rate by $9.89 \%$, thus increases the exergy losses of the system component. The exergy loss at the HPG shows different behavior by increasing the chilled water inlet temperature will reduces the exergy losses from $957.21 \mathrm{~kW}$ to $599.83 \mathrm{~kW}$. The increment of chilled water inlet temperature does not affect the mass flow rate of the steam. The increasing value of the working fluid mass flow rate that thermodynamically reacts with the constant value of steam mass flow rate will reduces the exergy loss at the HPG component. The circulation ratio (CR) for the system remains constant due to the increasing mass flow rate of refrigerant vapor which also increasing the mass flow rate of the weak lithium bromide solution. The increase of total exergy losses of the system is also related to the chilled water inlet temperature [18].

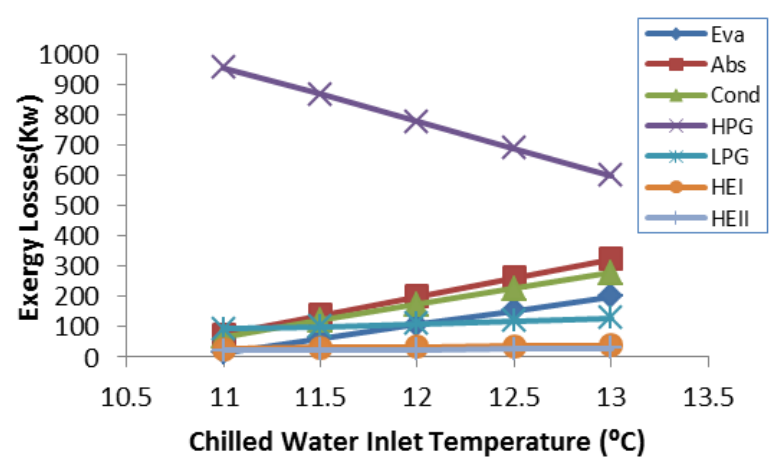

Fig. 8. Exergy losses vs. chilled water inlet temperature for system component

- Load Factor: Fig. 9 shows the different value of COP and ECOP with the variation of load factor. The load factor is increased by manipulating the mass flow rate of the chilled water. The COP increases due to the fact that the cooling effect in the evaporator increases with the increasing of chilled water mass flow rate. 
The COP is expected to increase more with the increase of load factor. The ECOP of the system also increases from 0.26 to 0.34 due to the fact that the absorption cooling system has higher exegetic efficiency at lower operating temperature. The increase in mass flow rate will increase the potential to create the cooling effect at higher rate than before. Similar to COP, ECOP is also expected to increase with the increase of load factor.

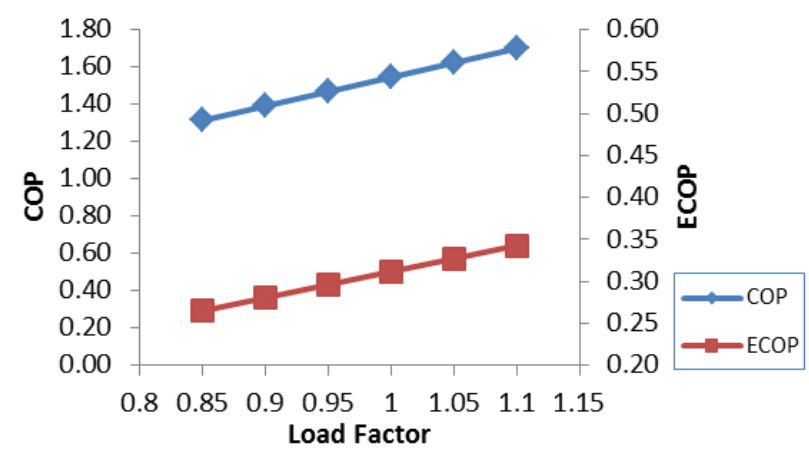

Fig. 9. COP \& ECOP vs. Load Factor

Fig. 10 shows the different value of exergy losses at different system component with the variation of load factor. The increase of load factor by 0.05 will increase the system mass flow rate by $5.80 \%$. The exergy loss at the absorber and condenser component increase rapidly with the load factor variation. This can be explained with the mixing losses at the evaporator and the increase in cooling capacity to condense the refrigerant vapor in the condenser. The exergy loss at the other component slightly increases due to high efficiency of the heat transfer and low temperature difference between the water and lithium bromide solution. For the exergy losses at the HPG, it shows a different behavior. The reason for this behavior is already explained in the previous section in which the load factor increase does not affect the mass flow rate of steam; thus it reduces the exergy loss from $796.77 \mathrm{~kW}$ to $483.20 \mathrm{~kW}$. However, the total exergy losses of the system increases with the increment of load factor and this shows a good agreement with the study conducted by [16].

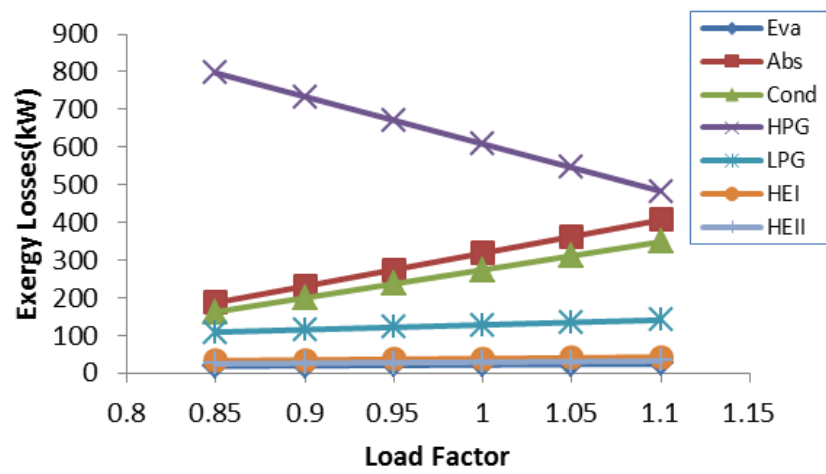

Fig. 10. Exergy losses vs. load factor for system components

\section{CONCLUSION}

In this paper, the thermodynamic analysis for energy and exergy was carried out. The performance of the SAC system at PJ1 plant was monitored based on the COP, ECOP and Load Factor (LF) for a week period. Based on the system study, several conclusions have been made:

i. The average COP lies in the range of 1.24-1.69, average
ECOP lies in the range of $0.252-0.269$ and the LF lies in the range of $0.879-1.136$ which show that the SAC system is in good working condition.

ii. For the exergy loss of the component, the HPG contributed the highest exergy losses followed by the absorber and the condenser. It shows that the HPG is the main important component in the SAC and it gives the highest effect on the system performance.

iii. The COP increasing slightly with the manipulation of steam inlet temperature. The increasing of steam inlet temperature reduces the temperatures difference between the working fluid. ECOP decreases slightly due to highest exergy losses in the generator.

iv. The COP increases rapidly by the manipulation of chilled water inlet temperature which shows the producing cooling capacity will increase the energy flows in the evaporator. From different point of view, ECOP decreases slightly as the lower operating temperature has high potential to create the cooling effect.

v. The COP and ECOP increase with the increment of the load factor. This can be explained with the fact that the COP and ECOP operate well in lower operating temperature with the increase of chilled water mass flow rate.

vi. The manipulation for the variable operating conditions increases the total exergy loss of the system.

\section{REFERENCES}

1. S. Haron, "Implementation of Gas District Cooling and Cogeneration System In Malaysia", Gas District Cooling (M) Sdn Bhd, Malaysia, ( March. 28, 2014) Accessed on: Sept. 27, 2018 [Online].Available: https://www.scribd.com/document/215113074/Implementation-of-GasDistrict-Cooling-and-Co-generation-Systems-in-Malaysia

2. K.Thirakomen, "Cogeneration and the new era of absorption chiller," AHSRAE Thailand Chapter, (Sept. 8, 2001). Accesed on: Nov. 5, 2018 [Online] Available: http://www.ashraethailand.org/download/ashraethailand_org/pub_2001 0908co-gen.pdf

3. I.Horuz, "A comparison between ammonia-water and water-lithium bromide solutions in vapor absorption refrigeration systems," Int. Comm. Heat Mass Transfer, Vol. 25, No. 5, 1998, pp. 711 - 721.

4. P. Srikhirin, S. Aphornratana and S. Chungpaibulpatana, "A review of absorption refrigeration technology," Renewable and Sustainable Energy Reviews, Vol. 5, 2001, pp. 343 - 372.

5. S.C. Kaushik, and A. Arora, "Energy \& Exergy analysis of single effect and series flow double effect LithiumBromide/Water absorption refrigeration system, "International Journal of Refrigerant, Vol. 32, No. 6, 2009, pp. $1247-1258$.

6. C.M.Lamine and Z. Said, "Energy analysis of single effect absorption chiller in an industrial manufacturing of detergent," Energy Procedia, Vol. 50, 2014, pp. $105-112$.

7. H.Yin, M. Qu and D.H.Archer, "Model based experimental performance analysis of a microscale $\mathrm{LiBr} / \mathrm{H} 2 \mathrm{O}$ steam-driven double-effect absorption chiller," Applied Thermal Engineering, Vol. 30, 2009, pp. 1741-1750.

8. O. Kaynakli, U. Unver and M. Kilic, "Exergy analysis of a lithium bromide / water absorption refrigeration system," International Energy Exergy and Environment Symposium, At Izmir, Turkey, July 2013.

9. F. P. Zadeh, "The energy and exergy analysis at single effect absorption chiller," International Journal Advanced Design and Manufacturing Technology, Vol. 4, No. 4, 2011, pp. 19 - 26.

10. B. H. Gebrelassie, M. Medrano and D. Boer, "Exergy analysis of multi effect absorption cooling system: From half to triple effect," Renewable Energy, Vol. 35, 2010, pp. 1773 - 1782.

11. M. Kilic and O. Kaynakli, "Second law-based thermodynamics analysis of water-lithium bromide absorption refrigeration system," Energy, Vol. 32, No. 8, 2007, pp. 1502 - 1512. 
12. S. Mohtaram, W. Chen and J. Lin, "A study on an absorption refrigeration cycle by exergy analysis," 9th International Conference on Environmental Science and Technology, Vol. 182, 2018.

13. M. Mehyo, H. Ozcan, and A. Hassan, "Thermodynamic Analysis of a Power Plant Waste Heat Driven Absorption Refrigeration System," Proceedings of the 4th World Congress on Mechanical, Chemical, and Material Engineering (MCM'18) Madrid, Spain - August 16 - 18, 2018.

14. A. Lake, B. Rezaie and S. Beyerlein, "Use of Exergy Analysis to Quantify the Effect of Lithium Bromide Concentration in an Absorption Chiller," Entropy, Vol. 19, No. 156, 2017, pp. 1 - 16.

15. A. Ameen, "Appendix B," in Refrigeration and Air Conditioning, Eastern Economy Edition, New Delhi: A. K. Ghosh, PHI Learning Private Limited, 2012, pp. 479 - 499.

16. M.S. Ahmed and S. I. U. Gilani, "Exergy analysis of a Double-Effect parallel flow commercial steam absorption chiller," Journal of Applied Sciences, Vol. 12, No. 20, 2012, pp. 2580 -2585.

17. S. Sedigh, H. Saffari, H. Taleshbahrami, "Thermodynamic analysis of double effect absorption system along with boiler and cooling tower," J. Environ. Sci. Eng. A, Vol.1, No. 2, 2012, pp. 261-270.

18. A. Sencan, K. A. Yakut and S. A. Kalogirou, "Exergy analysis of lithium bromide/water absorption system," Renewable Energy, Vol. 30, No. 5 , 2005 , pp. $261-270$

19. M. B. Arun, M. P. Maiya and S. S. Murthy, "Performance comparison of double -effect parallel-flow and series fow water-lithium bromide absorption system," Applied Thermal Eng, Vol. 21, No. 12, 2001, pp. $1273-1279$.

\section{AUTHORS PROFILE}

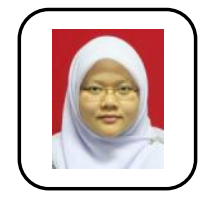

Rosnadiah Bahsan is a Senior lecturer at Faculty of Mechanical Engineering, Universiti Teknologi MARA (UiTM), Malaysia. Author area of interest in Power Plant Engineering, Heat Trasnfer, Solar Power and Engineering Education. Board of Engineers Malaysia (BEM) membership.

Khairul Aizat Mohd Sarudin is an Operations Executive at Suria KLCC Sdn. Bhd. Holding a Bachelor of Engineering (Hons) (Mechanical) from Universiti Teknologi MARA (UiTM), Malaysia. Board of Engineers Malaysia (BEM) membership.

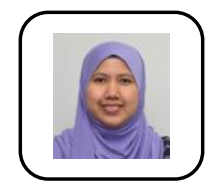

Nor Merlisa Ali is a senior lecturer at Faculty of Mechanical Engineering, Universiti Teknologi MARA (UiTM), Malaysia. Author area of interest in Experimental and Computational Fluid Mechanics; Natural Ventilation; Fluid Flow, Urban Physics, Buildings Aerodynamics, Indoor Air Quality and Thermal Comfort. Board of Engineers Malaysia (BEM) membership.

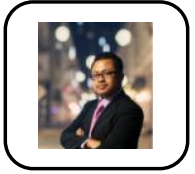

Ts. Dr. Syamsul Nor Azlan Mohamad is a senior lecturer at Faculty of Education, Universiti Teknologi MARA (UiTM), Malaysia. Holding a Phd in Education (IT,and Computing Education) and Master in Educational Technology. Now, he is a Head of Assessment and Evaluation in Universiti Teknologi MARA. He actively engaged with KPM, KPT, Apple.Inc, MDEC, IBM, HP, Dreamcatcher, public and private universities for research and consultation for digital maker talent and innovation initiative. His area of research includes engineering education, curriculum review, e-Portfolio/alternative assessment, learning and predictive analysis. 